\title{
Hybrid zone maintenance by non-adaptive mate choice
}

\author{
Anders Brodin · Fredrik Haas
}

Published online: 13 December 2007

(C) Springer Science+Business Media B.V. 2007

\section{Erratum to: Evol Ecol}

\section{DOI 10.1007/s10682-007-9173-9}

On pages 8 and 9 the following text "We have plotted the two modifications of the baseline version that we visually judged to fit the hybrid zone best, the 4 times multiplication from Fig. 4 (Fig. 7a) and alternative 4 from Fig. 5 (Fig. 7b)." Should read:

"We have plotted the two modifications of the baseline version that we visually judged to fit the hybrid zone best, the 4 times multiplication from Fig. 5 (Fig. 7a) and alternative 4 from Fig. 6 (Fig. 7b)."

On page 9 the following Fig. 7 caption "Fig. 7 The simulation clines that agreed best with field data. a) shows case 4 from Fig. 4, b) shows case 4 from Fig. 5" should read:

Fig. 7 The simulation clines that agreed best with field data. a) shows case 4 from Fig. 5 , b) shows case 4 from Fig. 6 .

The online version of the original article can be found under doi:10.1007/s10682-007-9173-9.

A. Brodin $(\bowtie) \cdot$ F. Haas

Division of Theoretical Ecology, Department of Ecology, Ecology Building, Lund University, 22362 Lund, Sweden

e-mail: Anders.Brodin@teorekol.lu.se 